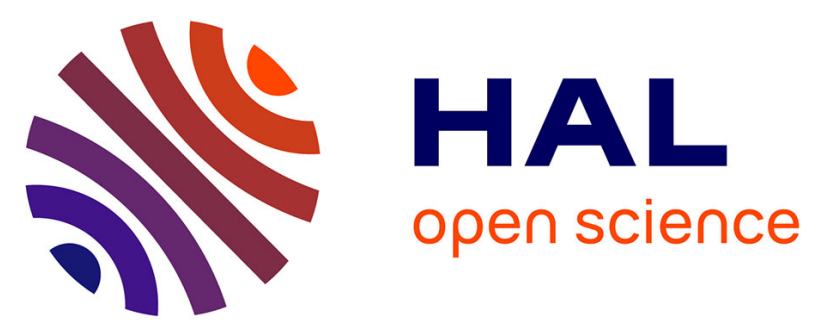

\title{
A Review of Integrated Approaches for Material, Design and Process Selection and a Proposal for the AM Processes
}

\author{
Manuela Galati, Flaviana Calignano, Luca Iuliano
}

\section{To cite this version:}

Manuela Galati, Flaviana Calignano, Luca Iuliano. A Review of Integrated Approaches for Material, Design and Process Selection and a Proposal for the AM Processes. 15th IFIP International Conference on Product Lifecycle Management (PLM), Jul 2018, Turin, Italy. pp.747-756, 10.1007/978-3-03001614-2_68. hal-02075621

\section{HAL Id: hal-02075621 \\ https://hal.inria.fr/hal-02075621}

Submitted on 21 Mar 2019

HAL is a multi-disciplinary open access archive for the deposit and dissemination of scientific research documents, whether they are published or not. The documents may come from teaching and research institutions in France or abroad, or from public or private research centers.
L'archive ouverte pluridisciplinaire HAL, est destinée au dépôt et à la diffusion de documents scientifiques de niveau recherche, publiés ou non, émanant des établissements d'enseignement et de recherche français ou étrangers, des laboratoires publics ou privés. 


\title{
A review of integrated approaches for material, design and process selection and a proposal for the $A M$ processes
}

\author{
Manuela Galati, Flaviana Calignano, Luca Iuliano \\ Politecnico di Torino, Corso Duca Degli Abruzzi 24, 10129 Torino, Italy \\ manuela.galati@polito.it, flaviana.calignano@polito.it, \\ luca.iulianoepolito.it
}

\begin{abstract}
The comprehensive approach to the development of a product should analysis all of the phases, from the design to the manufacturing for the selection of a good combination of materials, designs and manufacturing processes. Due to the complexity of addressing an all-inclusive problem, the decision is usually entrusted to the manufacturing engineers for which products that have producible features easily and simple geometries are desirable, even if sacrificing the component performances. However, today, Additive Manufacturing (AM) processes offer a wide degree of design freedom that allows overcoming the traditional manufacturing limitations.

The aim of this paper is to provide a thorough review of the process selection (PS) approaches by taking into account manufacturing technologies in conjunction with the material and design performance. The paper attempts to provide as result a basic and generic methodology, which provides guidelines for the effective introduction of the AM processes in the process selection problem.
\end{abstract}

\section{Introduction}

A designer has the responsibility of ensuring the conformity of a product according to the specifications indicated by the customers and ensuring the quality of the product from manufacturing to assembly while limiting time and costs [1-3]. From this point of view, sets of design rules have been drawn up to guide designers on the feasibility of their designs [4], such as the Design for Manufacture (DfM). DfM states that designers must adapt their designs taking into account manufacturing problems [5, 6], in order to eliminate any manufacturing difficulties, and minimize the manufacturing operations, assembly and costs $[7,8]$. That integrated approach, known as concurrent or simultaneous engineering $(\mathrm{CE})$, can aid industrial engineers in the success of this issue. $\mathrm{CE}$ is a methodology of designing and developing products, in which the different stages run simultaneously, rather than consecutively. On example of the practical application of $\mathrm{CE}$ is the development of the process selection (PS) tools, which work by allowing the designer to select the best manufacturing resource to produce a specific part. However, decisions become difficult when the design stage is affected by numerous uncertainties

adfa, p. 1, 2011.

(C) Springer-Verlag Berlin Heidelberg 2011 
as for the definition of the manufacturing process as well as specifications of the mechanical and functional requirements. In fact, due to DfM rules, the end of design stage can be established once the manufacturing process is defined. In addition, at the beginning of the design stage, some specification could be evaluated only approximately [9]. For example, several materials could be excluded from the process selection because the production unfeasibility even if they satisfied the performance requirements. Therefore, potentially the decision-making activity about the selection of material and manufacturing processes should precede design stage. On the other hand, the design of the part should be the first input in order to select at least one manufacturing process and explore its feasibility [3]. As a consequence, a complex relationship results between designs, materials and manufacturing processes [9]. Therefore, the choice is often entrusted to the manufacturing engineers which modify the initial design according to their personal knowledge and background $[9,10]$ in order to producible features even sacrificing the part performances. Recently, Additive Manufacturing (AM) has revolutionised the manufacturing approach, because it offers the possibility of manufacturing parts of any geometric complexity without using additional tools or machines [11]. The advantage of AM over conventional subtractive or formative methods is clearly illustrated by the great design freedom that can be achieved [12], such as the possibility of producing customised geometries or topologically optimized geometries for lightweight components. AM processes allow increased flexibility, compared to the production costs and lead-times of traditional manufacturing [13]. Particularly for the metal components, current AM technologies permit the manufacturing of complex endusable parts [13-15].

The aim of this paper is to provide a thorough review of PS approaches by taking into account manufacturing technologies in conjunction with the material and design performance. A basic, generic methodology is also proposed in light of the developing of a PS tool for the selection of the better manufacturing resource to produce a component that includes the AM processes. This led to a PS tool based on an all-inclusive methodology. The tool thus considers the combination of three elements: material, design and manufacturing process to determine the better alternative to produce the part.

\section{$2 \quad$ Literature Review}

The first approaches of developing a PS tool based on an integrated approach between design, materials and manufacturing processes $[16,17]$ used reference parts as an example of the optimal part to be produced with a specific manufacturing system. Ishii, Adler [16] presented the simplest selection in which the best technology resource was selected by comparing the part to be produced with the database of the reference parts. Boothroyd [17] introduced the importance to take into account manufacturing processes already at the design stage. He provided a review of published and successful case studies in which quite geometry modifications have been applied in order to improve the match between the design and the process constraints. However, since this kind of PS tools were developed on the base of real case studies[16, 17], they can be helpful only when a small range of geometries, materials [18] and manufacturing processes [10] can 
be considered. In fact, while this approach allows to trade off some process from the selection problem, it does not give a quantitative comparison among the remained alternatives and a unique solution of selection problem [9]. Swift and Booker [3] introduced the first structured approach based on several matrixes in which the capability of 65 manufacturing processes have been included. The method was called PS maps (PRIMAs) and it worked by selecting the process that satisfies the design specifications. Practically, in each matrix, the processes are classified according to the satisfaction of a specific requirement such as processable materials. The selection is obtained by matching the requirements of the design against the capability of the process. However, due to the uncertainty of the design at the design stage, the authors highlighted that the intention of this methodology have been just proving a guide for the selection of some processes which could the most appropriate candidates to produce that component. Poli [19] compared polymer processing, metal casting, and sheet metal forming not only from a design point of view but also considering the manufacturing costs. Pursuing this line of work, Boothroyd, Dewhurst [20] also included machining, casting and injection moulding processes into the PS analysis. Both books [19, 20] reported a detailed review of the DfM rules in order to analyses an integrated material and manufacturing process problem. DfM rules have been collected for each process. The selection were performed by matching the design and its requirements with the constraints of the manufacturing process. Boothroyd, Dewhurst [20] addressed the comparison between all processes using a production rule and pattern matching and Poli [19] provided a methodology for the selection of materials and processes for special purpose parts using tables and charts that would aid the designer throughout the design process and during the evaluation of the manufacturing alternatives. Because all of these approaches considered a qualitative assessment of the design specification, a ranking between alternatives appears difficult. Giachetti [9] presented an integrated multi-criteria decision (MAMPS) where the fuzzy logic has been applied to address the uncertainties of the requirements. In this case, a quantitative scale has been considered in order to convert the qualitative assessment given to each criterion. Precompiled databases have provided in order to avoid the effect of personal background and the final evaluations have been aggregated using a weighted geometric mean. A similar approach was adopted by Yu, Krizan [10] in which several variables have been considered. Those variables have been grouped into three categories: material, design features, and manufacturing variables. Each category has an independent classification. The three obtained classifications have been aggregated in order to obtain a unique ranking. Both of the studies $[9,10]$ neglected the effects of correlated variables that could contribute with redundant information when the variables are aggregated into a unique score. Among the used variables, processing cost for each part would appear strongly correlated with the material as well as the weight of the part with the density and the material cost. In addition, the qualitative indicators have been used by entrusting the evaluation to the individual's background. Therefore, that evaluation could result filtered through the personal experiences of the evaluator in a specific manufacturing process.

Until now, AM processes have been excluded from the comparison with other manufacturing processes because the rapid prototyping has been considered their only application for many years [21]. Deglin and Bernard [22] dealt a knowledge-based system 
for the selection of a most proper process to prototype components rapidly. Wilson and Rosen [23] and successively Gibson, Rosen [24] addressed the process selection for metal AM processes using a quantitative approach. The considered variables have been aggregated by using a weighted sum formulation. The alternatives have been ranked according to the achieved score. Since no guideline was provided about how to weight the variables, the authors suggested running a sensitivity analysis to determine how different values of the weights impact the final ranking. Samperi [25] dealt the comparison between metal AM processes following the classical approach where the design rules are matched with the design specifications. However, variables as the build time or cost estimations have been neglected. In order to extend the decision problem to the AM processes, uz Zaman, Siadat [26] suggested a first methodology that allowed to compare different $\mathrm{AM}$ and traditional manufacturing processes using three design criteria: function, cost and environment. Even in this case, a single value was used to aggregate the variables. Some comparison for the selection of the best technology resource in the case of AM processes was presented as a case study. Some of these showed the effectiveness of AM process for low production volume if compared with high pressure die casting [27], an improving of the supply chain in the reduction of lead time and the total cost [28], a reduction buy-to-fly ratio for the aero engine if compared with machining [29]. However, those approaches cannot constitute an effective guideline for the process selection because of the lack of general guidelines.

All of the review models utilised the same geometry as input for each analyzed process, and no design optimisation has been considered. Instead, the redesign of the part [30] is today recognized as a mandatory step to exploit the advantages of AM processes. The applications of AM processes without change the classical approach could be lead to erroneous solutions that in turn results in the abandonment of the technology due to, for instance, excessive pricing. Therefore, at the state of the art, no all-inclusive PS tool compares the AM with the other manufacturing systems while the proper characteristics introduced by AM in the manufacturing/design world are considered.

\section{Proposed PS tool}

AM was recently recognized as manufacturing processes with exclusive benefits [31] especially to produce metal parts. For this reason, there is the need to develop of a proper decision model that can consider the benefits of the AM process in the comparison with the others manufacturing processes and can be helpful already in the design stage. When the AM processes are considered in a PS problem, there is some aspect that must be addressed with particular attention. One of these concerns the manufacturing cost per part, which was used as the only factor that drives the process selection in the existing literature models. However, currently, the parts produced by AM processes are often not competitive in terms of manufacturing costs. This should be explained because the geometry is not performed for AM process, the high price of the powder compared the ingot, and/or the high machine cost. 
In the light of the in-depth literature survey and the current development of the metal AM processes, the proposed PS tool (Fig.1) compares different manufacturing processes, including AM processes by:

- Taking into account the design for the part performance and the design for manufacturing

- Considering a quantitative evaluation in order to exclude personal assessments

- Considering a broader analysis of the effectiveness of the design and its specification not only limited to the part but toward the effects on the whole system

Considering two independent ranks: one for the technical aspects and one for the manufacturing costs, in order to avoid redundant information and give a comprehensive description of the decision problem. The tool operates using panel and subpanels based on the consideration of three key factors: the material, the design of the component, and the ranking of the alternatives. The basic requirements to implement this suggested procedure are two databases: one that contains the manufacturing processes and the machines that are available (or to be evaluated) for a specific manufacturing process and one that contains the materials that are available (or to be evaluated) for a specific manufacturing process.

The Input panel collects the data and specification of the component such as information about the basic geometry, the minimum requirements for the material and for the design and the estimated quantity to be produced.

The Elaboration of input data panel extracts the information from the Input panel about the maximum envelope of the part, the tolerances, the roughness and heat treatments required for the components. In this step, a preliminary screening is run. The build volume of each available machine is compared with the maximum envelope of the part. The machine and the manufacturing process is collected is they match the requirement. On the contrary, it is possible to evaluate other orientations of the part in the build volume and/or the splitting of the part into two or more components. As far as the material is concerned the properties of each material are compared with the technical specifications for minimum elastic module, hardness and yield stress. Post heat treatment operations on the material are considered to improve the material proprieties and collected. From this step, two new databases are compiled. The first one contains the processes for which at least one machine is able to produce the part geometry. This database also includes information about the assembly, if it is necessary. The second database contains the materials that matched the requirements and heat treatments if they are needed.

The Preselection panel works to establish the process/material couples that can be proper to produce the part. Each material is compared with the capabilities of each process. In addition, because the information that derived from preliminary process preselection could contain assembly operations, the compatibility of the material with the assembly operations is checked.

The Design and Manufacturability analysis panel is the stage of the process selection that represents the core of the feasibility analysis. The material and the manufacturing specification converge to the first process selection in which the geometry is matched with the DfM rules. The basic operations to obtain the part are defined. This phase 
involves considering a design stage in which design methodologies, such as topology optimisation (TO), are applied to search the best performance of the component. This step is the most important to the success of the AM processes. Generally, the designer provides geometries already simplified in order to avoid high manufacturing costs or features that are obviously unfeasible. These considerations are almost fully irrelevant

Fig. 1. Proposed PS tool

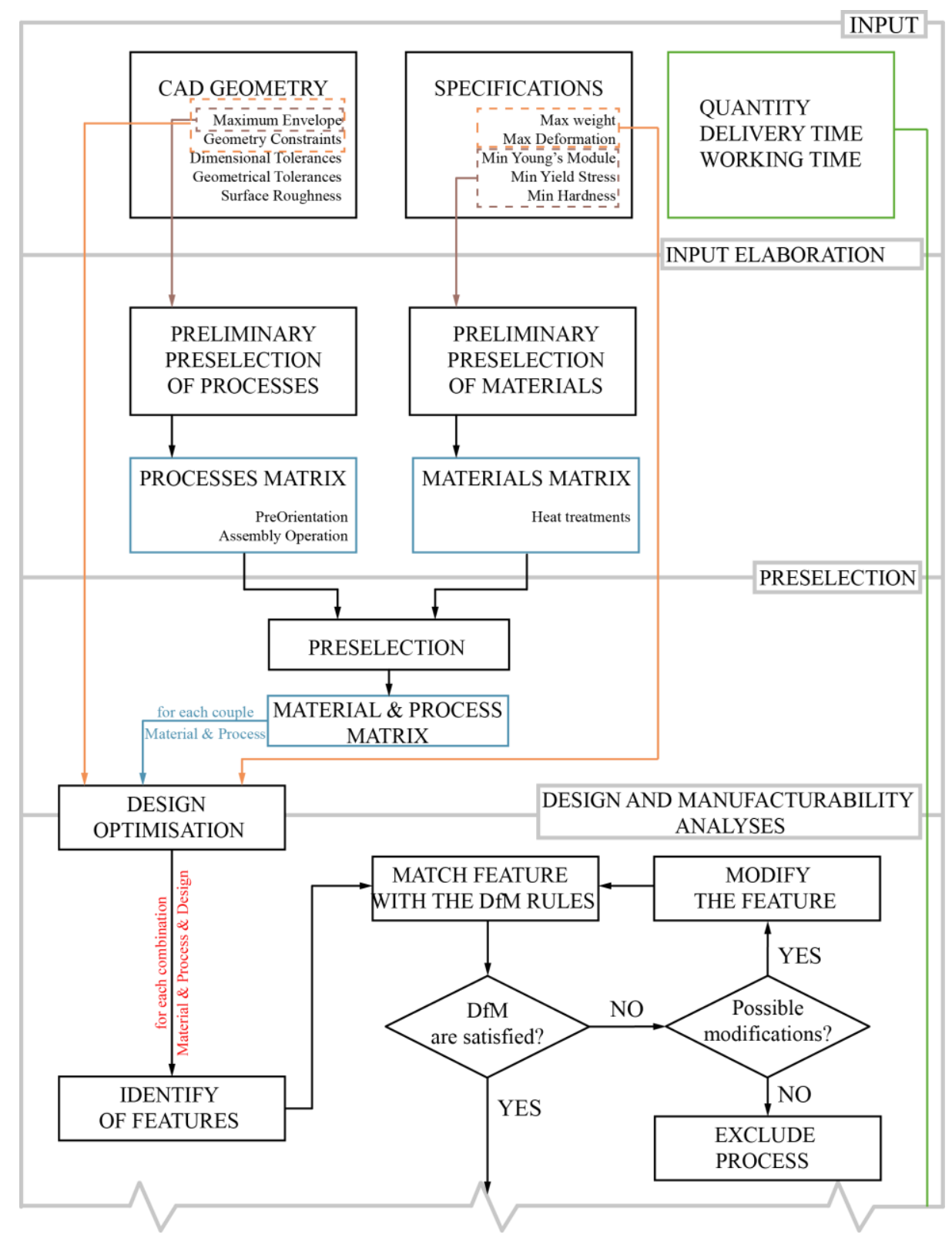




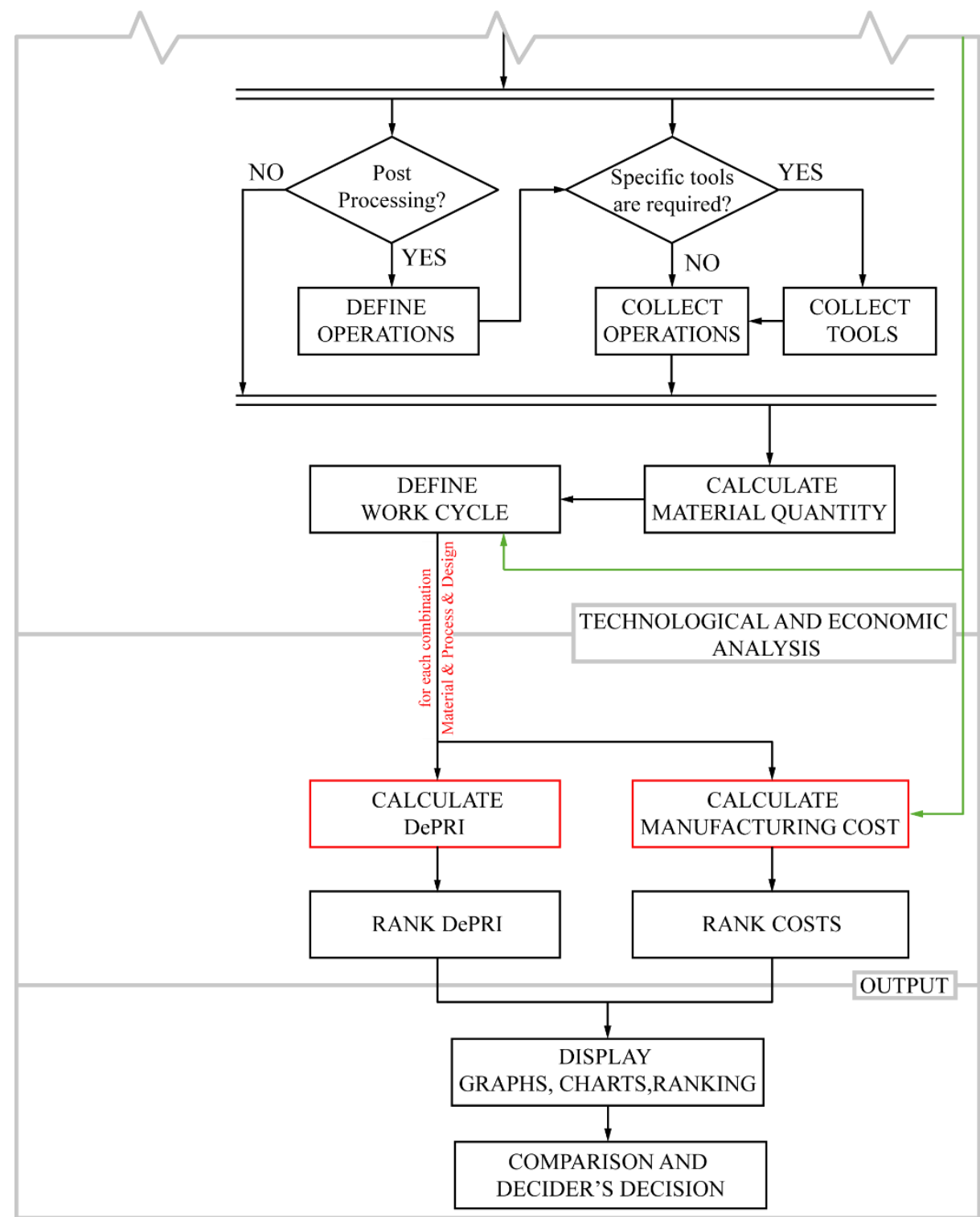

for AM processes because the increasing geometry complexity is not strongly correlated to an increasing of tge cost for an additive production.

The Technical and Economic analysis panel provides the technical index and the manufacturing cost per part. This two information are kept expressly independent in order to avoid redundant information and to provide a general overview and clearer results of the process selection phase. The technical or Design and Process Performance Index index (DePrI) is aimed to the comparison the manufacturing processes from a technical point of view. The index evaluates attributes grouped into three categories: material performances, design performances and process capabilities. An example of 
the evaluable attributes is given in Table 1. Each attribute should be weighted according to the design requirements. Therefore, DePrI can be computed using the weighted sum formulation. The rank in descending order will collect the alternatives from the most favourable to the least. The attempt is to obtain an indicator that not only can suggest what is the proper manufacturing process to produce the part but also what manufacturing process could allow the production of a part with the best performance.

For this reason, DePrI can be used for several purposes not least for as to "weight" the cost per part. In fact, that definition takes into account the hidden effect of considering a combination of material, design and manufacturing process. Therefore, this value is also a "measure" of the benefits that could be achieved by adopting the new geometry (material and process).

The last one is the Output panel that should provide the decider a quantitative analysis together with chart and graphs in order to support decisions.

Table 1. Example of evaluable attributes by using DePrI

\begin{tabular}{ll}
\hline Material performances & Attributes \\
& $\begin{array}{l}\text { Strength of the material } \\
\text { Stiffness of the material } \\
\text { Hardness of the material } \\
\text { Gesign performances }\end{array}$ \\
& $\begin{array}{l}\text { Geometric complexity of the design } \\
\text { Capabilities of the design to satisfy the required } \\
\text { weight of the part } \\
\text { Capabilities of the design to satisfy the required con- } \\
\text { straint on the maximum displacement of the part in all } \\
\text { load conditions weight of the part } \\
\text { Capabilities of the process to produce the required } \\
\text { holes without finishing operations } \\
\text { Capabilities of the process to produce surfaces with } \\
\text { the prescribed roughness without finishing operations } \\
\text { Capabilities of the process to produce features with the } \\
\text { prescribed tolerances without finishing operations } \\
\text { Capabilities of the process to produce the part in the } \\
\text { delivery time }\end{array}$ \\
\hline
\end{tabular}

\section{Conclusion}

A literature review was made in the field of the PS tools in order to identify the shortcoming and limits of applicability when the AM processes are included in the PS strategy. It was concluded that there is no PS tool that can consider properly the advantages of the adopting of the AM processes. The main weaknesses of the literature approaches were found on the using the same geometry as main input for the process selection and the use of costs-driven methods for the process selection. In light of that, a new framework was introduced in order to provide an index to compare the alternatives, considering not only the manufacturing cost but also the features and the specification of the 
best design that can be obtained using the manufacturing process. The proposed PS tool is, therefore, an all-inclusive methodology between material, process and design that considers the combination of these elements to determine the best alternative to produce the part. The evaluation must be carried out by using DePrI and the manufacturing cost. DePrI is able to quantitative evaluate the performance of the design, material and process and it can be used as a weight for the information provides by of the manufacturing cost analysis in order to justify, for instance, an increase of cost manufacturing cost from the traditional to additive manufacturing. The proposed tool aims to facilitate the introduction of AM processes in the metal industry giving more sensibility of the peculiarity of the AM processes as regards the design optimisation.

\section{Bibliography}

1. Anderson, D.M., Design for manufacturability: optimizing cost, quality, and time to market. 2001: CIM press.

2. O’Driscoll, M., Design for manufacture. Journal of materials processing technology, 2002. 122(2): p. 318-321 DOI: https://doi.org/10.1016/S0924-0136(01)01132-.

3. Swift, K.G. and J.D. Booker, Process selection: from design to manufacture. 2003: Butterworth-Heinemann.

4. Edwards, K., Towards more strategic product design for manufacture and assembly: priorities for concurrent engineering. Materials \& design, 2002. 23(7): p. 651-656 DOI: https://doi.org/10.1016/S0261-3069(02)00050-X.

5. Kerbrat, O., P. Mognol, and J.-Y. Hascoët, A new DFM approach to combine machining and additive manufacturing. Computers in Industry, 2011. 62(7): p. 684-692 DOI: https://doi.org/10.1016/j.compind.2011.04.003.

6. Shukor, S.A. and D. Axinte, Manufacturability analysis system: issues and future trends. International Journal of Production Research, 2009. 47(5): p. 1369-1390 DOI: https://doi.org/10.1080/00207540701589398.

7. Gibson, I., D.W. Rosen, and B. Stucker, Design for additive manufacturing, in Additive Manufacturing Technologies. 2010, Springer. p. 299-332.

8. Zhou, M., R. Fleury, Y.-K. Shyy, H. Thomas, and J. Brennan. Progress in topology optimization with manufacturing constraints. in Proceedings of the 9th AIAA MDO conference AIAA-2002-4901. 2002.

9. Giachetti, R.E., A decision support system for material and manufacturing process selection. Journal of Intelligent Manufacturing, 1998. 9(3): p. 265-276 DOI: https://doi.org/10.1023/A:1008866732609.

10. Yu, J.-C., S. Krizan, and K. Ishii, Computer-aided design for manufacturing process selection. Journal of Intelligent Manufacturing, 1993. 4(3): p. 199-208 DOI: https://doi.org/10.1007/BF00123964.

11. Galati, M. and L. Iuliano, A literature review of powder-based electron beam melting focusing on numerical simulations. Additive Manufacturing, 2017 DOI: https://doi.org/10.1016/j.addma.2017.11.001

12. Gibson, I., D.W. Rosen, and B. Stucker, Additive manufacturing technologies. 2010: Springer.

13. Wohlers, T., Additive Manufacturing State of the Industry in Wohlers Report 2014: Fort Collins, USA. 
14. Das, S., Physical Aspects of Process Control in Selective Laser Sintering of Metals. Advanced Engineering Materials, 2003. 5(10): p. 701-711 DOI: https://doi.org/10.1002/adem.200310099.

15. Larsson Morgan, L.U., Harrysson Ola. Rapid manufacturing with electron beam melting (EBM) - A manufacturing revolution? in Solid freeform fabrication symposium. 2003. Austin, TX.

16. Ishii, K., R. Adler, and P. Barkan, Application of design compatibility analysis to simultaneous engineering. Artificial Intelligence for Engineering, Design, Analysis and Manufacturing, 1988. 2(01): p. 53-65 DOI: https://doi.org/10.1017/S0890060400000548.

17. Boothroyd, G., Product design for manufacture and assembly. Computer-Aided Design, 1994. 26(7): p. 505-520 DOI: https://doi.org/10.1016/0010-4485(94)90082-.

18. Beiter, K., S. Krizan, K. Ishii, and L. Hornberger, HyperQ/Plastics: An intelligent design aid for plastic material selection. Advances in Engineering Software, 1993. 16(1): p. 53-60 DOI: https://doi.org/10.1016/0965-9978(93)90029-S.

19. Poli, C., Design for manufacturing: a structured approach. Vol. 1. 2001: ButterworthHeinemann.

20. Boothroyd, G., P. Dewhurst, and W.A. Knight, Product design for manufacture and assembly. 2010: CRC press.

21. Campbell, I., D. Bourell, and I. Gibson, Additive manufacturing: rapid prototyping comes of age. Rapid prototyping journal, 2012. 18(4): p. 255-258 DOI: https://doi.org/10.1108/13552541211231563.

22. Deglin, A. and A. Bernard, A knowledge-based environment for modelling and computeraided process planning of rapid manufacturing processes, in Integrated Design and Manufacturing in Mechanical Engineering. 2002, Springer. p. 85-92.

23. Wilson, J.O. and D. Rosen. Selection for rapid manufacturing under epistemic uncertainty. in ASME 2005 International Design Engineering Technical Conferences and Computers and Information in Engineering Conference. 2005. American Society of Mechanical Engineers.

24. Gibson, I., D. Rosen, and B. Stucker, Guidelines for Process Selection, in Additive Manufacturing Technologies. 2015, Springer. p. 303-327.

25. Samperi, M.T., Development of design guidelines for metal additive manufacturing and process selection. 2014, The Pennsylvania State University.

26. uz Zaman, U.K., A. Siadat, M. Rivette, A.A. Baqai, and L. Qiao, Integrated product-process design to suggest appropriate manufacturing technology: a review. The International Journal of Advanced Manufacturing Technology: p. 1-22.

27. Atzeni, E. and A. Salmi, Economics of additive manufacturing for end-usable metal parts. The International Journal of Advanced Manufacturing Technology, 2012. 62(9-12): p. 11471155 DOI: https://doi.org/10.1007/s00170-011-3878-1.

28. Professor Per Hilletofth, P.O.-P.H., A. Professor Yacan Wang, M.-C. Chiu, and Y.-H. Lin, Simulation based method considering design for additive manufacturing and supply chain: An empirical study of lamp industry. Industrial Management \& Data Systems, 2016. 116(2): p. 322-348 DOI: https://doi.org/10.1108/IMDS-07-2015-0266.

29. Allen, J., An investigation into the comparative costs of additive manufacture vs. machine from solid for aero engine parts. 2006, DTIC Document.

30. Salmi, A., F. Calignano, M. Galati, and E. Atzeni, An integrated design methodology for components produced by laser powder bed fusion (L-PBF) process. Virtual and Physical Prototyping, 2018: p. 1-12 DOI: https://doi.org/10.1080/17452759.2018.1442229.

31. Gibson, I., D.W. Rosen, and B. Stucker, Additive manufacturing technologies. Vol. 238. 2010: Springer. 